\title{
Erratum to: Groundwater Storage Changes: Present Status from GRACE Observations
}

\author{
Jianli Chen ${ }^{1} \cdot$ James S. Famiglietti ${ }^{2,3}$ • \\ Bridget R. Scanlon ${ }^{4} \cdot$ Matthew Rodell $^{5}$
}

(C) Springer Science+Business Media Dordrecht 2016

\section{Erratum to: Surv Geophys (2016) 37:397-417 \\ DOI 10.1007/s10712-015-9332-4}

In the original article, co-author Dr. James S. Famiglietti's last name was misspelled (an "i" was missing at the end).

Everything else in the paper remains correct.

The online version of the original article can be found under doi:10.1007/s10712-015-9332-4.

Jianli Chen

chen@csr.utexas.edu

Center for Space Research, University of Texas at Austin, Texas, TX 78759, USA

2 Jet Propulsion Laboratory, California Institute of Technology, Pasadena, CA 91109, USA

3 Department of Earth System Science, University of California, Irvine, CA 92697, USA

4 Bureau of Economic Geology, Jackson School of Geosciences, University of Texas at Austin, Texas, TX 78759, USA

5 Hydrological Sciences Laboratory, NASA Goddard Space Flight Center, Greenbelt, MD 20771, USA 